\title{
Erobots as research tools: Overcoming the ethical and methodological challenges of sexology
}

\author{
Simon Dubéa,*, Maria Santaguida ${ }^{\mathrm{a}}$ and Dave Anctil ${ }^{\mathrm{b}, \mathrm{c}, * *}$ \\ ${ }^{a}$ Concordia University, Department of Psychology, Montreal, Quebec, Canada \\ ${ }^{\mathrm{b}}$ Jean-de-Brebeuf College, Department of Philosophy, Montreal, Quebec, Canada \\ ${ }^{\mathrm{c}}$ Laval University, Canada
}

\begin{abstract}
Sexology faces several ethical and methodological challenges. One of them is that sex researchers must rely on proxy methods to safely study fundamental aspects of human sexuality - in laboratories and natural environments. However, laboratory studies often lack ecological validity, whereas studies conducted in natural environments make it difficult for researchers to control experimental conditions or use sophisticated equipment. Together, this puts into question some of the empirical foundations of contemporary sexology. To address this problem, the present article proposes that sex researchers could leverage the potential of emerging technology, like erobots - or artificial erotic agents, such virtual partners, erotic chatbots, and sex robots - to help overcome some of the current ethical and methodological challenges of sexology. To make this case, this article describes these challenges; highlights how erobotic technologies could be employed as research tools to conduct more ecologically valid sexological studies safely and ethically in and outside laboratory settings; and discusses the relative strengths and weaknesses of embodied, virtual, and augmented erobots as experimental apparatus in sex research. Ultimately, this article concludes that the development of erobots that are useful for sexology may require further collaboration between academia and the private sector. It also concludes that the development of such useful erobots may allow us to gain a deeper understanding of ourselves and our eroticism.
\end{abstract}

Keywords: Erobots, erobotics, sexology, ethics, methodology

\section{INTRODUCTION}

William Masters and Virginia Johnson revolutionized sexology - the study of human sexuality through their groundbreaking study of human sexual response, sexual disorders and dysfunctions (Masters \& Johnson, 1966, 1970). In their early days, these pioneers not only employed interviews or self-report questionnaires to examine the erotic experiences of their participants or patients, but also observed individuals directly engaging in solitary and partnered sexual activities, while various apparatus recorded their behaviors and physiological responses (Masters, Johnson, \& Kolodny, 1988, 1994). Masters and Johnson understood that the most efficient way to assess how the mind and body reacts during sex was to examine people engaging in intimate activities that approached - as closely as possible - real-world interactions.

Today, however, such methodology - and especially those involving partnered sex or intimate relationships in laboratories - would hardly meet the ethical standards of most research ethics boards due the psychological and physical risks associated with interhuman intimacy and sexuality. Hence, to make valuable scientific contributions to sexology, contemporary sex researchers must rely on alternative methods that meet such ethical standards - both in laboratories and natural environments. Yet,

\footnotetext{
*Corresponding author. E-mail: simondube.ta@gmail.com; Tel.: 1-514-618-1038.

** International Observatory on the Societal Impacts of Artificial Intelligence and Digital Technology, Laval University, Quebec, Quebec, Canada

2589-9953 @ 2022 - The authors. Published by IOS Press. This is an Open Access article distributed under the terms of the Creative Commons Attribution-NonCommercial License (CC BY-NC 4.0).
} 
the caveat is that laboratory studies often fall short of real-world sociosexual interactions (i.e., lack of ecological validity; Andrade, 2018), whereas studies conducted in natural environments make it difficult for researchers to control experimental conditions and use sophisticated laboratory apparatus (i.e., lack of control and access to equipment; Lehmiller, 2017). Together, the limitations of studies conducted in laboratories and natural environments call into question some of the empirical foundations of contemporary sexology. To address this problem, the present article proposes that sex researchers could leverage the potential of emerging technology, like erobots (erôs + bot $)$ - or artificial erotic agents, such as virtual companions, intimate chatbots, and sex robots - to help overcome some of the ethical and methodological challenges of sexology (Dubé \& Anctil, 2020).

To make this case, this article begins by describing said ethical and methodological challenges (Section 2). It then discusses erobotics - the study human-machine erotic interaction and co-evolution (Dubé \& Anctil, 2020) - and highlights how erobots could be employed as research tools to help ethically conduct more ecologically valid and controlled experiments in and outside laboratories (Section 3). It also explores the strengths and weaknesses of each taxon of erobots as sexological research tools (Section 4). Ultimately, this article concludes that the development of erobots that are useful to sexology may require further collaboration between academia and the private sector. It also concludes that these useful erobots may allow us to gain a deeper, holistic understanding of human eroticism.

\section{THE ETHICAL AND METHODOLOGICAL CHALLENGES OF SEXOLOGY}

Like other scientists, contemporary sex researchers must uphold the highest ethical standards in their scientific practices. This includes, for instance, ensuring that their work respects people and their autonomy; benefits individuals and societies, while simultaneously not harming them; as well as fairly distributing the benefits and risks associated with their research projects (Government of Canada, 2019). But, sex and intimate relationships between humans - ranging from flirting and courtship rituals, to partnered masturbation or sexual intercourse - can be sensitive and risky (Dir, Coskunpinar, \& Cyders, 2014; Scott-Sheldon et al., 2013). These can also be particularly difficult to navigate safely and ethically in laboratory settings or natural environments (cf., Binik, Mah, \& Kiesler, 1999; Masters, Johnson, \& Kolodny, 1977; Masters, Johnson, Kolodny, \& Weems, 1980; Munck, 1999; Price, Jansen, \& Weick, 2020; Riley \& Scott, 1999; Rosewarne, 2017; Rosoff, 2018; Shirmohammadi et al., 2018; Watter, 2020; Zhang et al., 2019). Hence, to protect research participants, and ensure that their studies comply with the ethical guidelines set by governments and research ethics boards, sex researchers must often rely on proxy or indirect methods to explore human sexuality.

Beyond the risks of harm, sexually transmitted or blood-borne infections and unintended pregnancies (Metcalfe et al., 2016; Mitchell et al., 2013), researchers must consider that people may not want to be intimate with one another, much less on cue in a laboratory where they may feel observed (Bloemers et al., 2010). Researchers must also consider that sexuality between humans can bring about issues related to pain, dysfunctions, harassment, assault, and complex emotional or relational dynamics, which can affect the health and well-being of individuals (Lehmiller, 2017) - i.e., research participants. What's more, the issue of consent can become difficult to navigate in contexts where some participants may feel pressured to take part in undesired sexual activities for the sake of science or because they are influenced by unintended power dynamics - e.g., experimenter-participant relations (Råheim et al., 2016). As a result, in recent decades, few studies have used experimental paradigms involving partnered sex in laboratory settings - and those that did were conducted in medical settings with monogamous heterosexual couples (Brody \& Krüger, 2006; Exton et al., 2001; Sidorkewicz \& McGill, 2014). 
But even if researchers may be able to design relatively safe studies involving partnered sex or intimacy, many darker aspects of human eroticism would remain difficult, if not impossible to ethically explore experimentally (Lehmiller, 2017). These may include any phenomena that may jeopardize the health and well-being of participants (e.g., experiments directly assessing sexual violence or its contributing factors; Davis et al., 2014). Moreover, we note that if the inclusion criterion to participate in studies exploring partnered sex or intimate relationships is that participants must be in committed relationships, it may prevent singles from contributing to sex research - here omitting a significant portion of the population, their experiences and data - while also limiting the scope of questions that can be investigated (e.g., the factors leading to the formation of said relationships).

For these reasons, sex researchers employ several alternative methods to explore human sexuality. These methods range from self-report questionnaires and validated scales, to interviews, daily diaries, and the use of archival or public databases (Lehmiller, 2017; Milhausen et al., 2020). In laboratory settings, these methods also include: inviting participants to fantasize, masturbate (Prause et al., 2016; Wise, Frangos, \& Komisaruk, 2017), and/or be exposed to erotic stimuli - such as sexually explicit videos, images, or audioclips (Chivers et al., 2010) - while instruments record their subjective, attentional, neurocognitive, or psychophysiological responses. These instruments may encompass but are not limited to: eye trackers (Wenzlaff, Briken, \& Dekker, 2016), heart rate and skin conductance monitors (Both, Brauer, \& Laan, 2011; Suschinsky \& Lalumière, 2012), electroencephalography (EEG; Ortigue, Patel, \& Bianchi-Demicheli, 2009), and functional magnetic resonance imaging (fMRI; Parada et al., 2018; Wise et al., 2017). To assess levels of sexual arousal, sex researchers may also record the genital responses of participants using penile and vaginal (photo)plethysmography, or respectively: a pressure-sensitive device that measures the circumference of the penis and a tamponshaped device which employs a light-based technique to assess the amount of blood in the vagina's walls (Huberman \& Chivers, 2015). More recently, researchers further employ genital thermography, a less invasive technique that assesses sexual arousal based on the surface temperature of the genitals (Parada et al., 2018).

Thus, in a typical experiment, sex researchers may ask participants to complete a battery of questionnaires at home, including questions about their demographics and sex life. Then, participants would come to the laboratory for an experimental session which may involve viewing a pornographic video and/or masturbating while their eye movements, brain activity, and/or genital temperature are recorded. Such experiments may further require participants to complete behavioral or cognitive tasks (e.g., prospective sexual behaviors, Stroop tasks, implicit association tests, or sexual imposition paradigms; Davis et al., 2014; Smith \& Waterman, 2005; Skakoon-Sparling, Cramer, \& Shuper, 2016; Sriram \& Greenwald, 2009). They may also involve study confederates or deception to help test the influence of certain variables onto participants' responses and mitigate social-desirability biases (i.e., people's tendency to respond in a manner that they think is desirable; Gueguen, 2009; PascualLeone, Singh, \& Scoboria, 2010; Zapien, 2017). Once the target sample size is achieved, researchers would then examine the statistical relationship between the different measures and draw implications or conclusions.

The main advantages of experiments conducted in laboratory settings are that researchers may have access to more sophisticated equipment and can better control or manipulate the different variables and experimental conditions in order to isolate their influence on human behaviors and responses (Lehmiller, 2017). However, laboratory experiments are constrained in time and their tasks and experimental conditions often markedly differ from the kind of erotic experiences - romantic, sexual, or otherwise intimate - that people have in their everyday life and real-world settings, such as: at home, alone or with a human partner. In turn, the current state of ecological validity of some experimental 
paradigms in sexology casts doubt upon the external validity and generalizability of the results obtained in human sex research (Rowland, 1999) - or the ability of apply these results to other, broader, and/or real-life erotic situations and groups (Andrade, 2018; Kite \& Whitley 2018; van Lankveld et al., 2014).

Specifically, taking aside the fact that laboratory settings can be distracting, research participants in sexuality studies are, for instance, typically exposed to sexual stimuli while their responses are being recorded, rather than actively having sex or engaging in intimate interactions with human partners (van Lankveld et al., 2014). This entails that several important elements of solitary or partnered sex and intimacy are missing. These include but are not limited to: privacy, the sensations associated with self or reciprocal touch, synchronized movement, kissing and embrace, penetration or genital caresses, discussions, along with the heat, noise, odor, and potential closeness, connection, or intimacy with a partner (Rowland, 1999). Yet, these elements may play a central role in people's erotic experiences and contribute to their sexual responses (e.g., arousal, desire, pleasure, and orgasm; Basson, 2000).

Thus, as an alternative, researchers sometimes rely on other methods, which allow them to investigate human sexuality in the natural environments of participants. For example, daily diary studies may ask participants to: perform specific tasks or behaviors; monitor some aspects of their relationships, sexuality, or health; and periodically complete questionnaires from the comfort of their home (Gunthert \& Wenze, 2012; Vaillancourt-Morel et al., 2020). Other researchers have also developed ambulatory psychophysiological laboratories to assess the genital responses of participants - i.e., vaginal pulse amplitude and clitoral blood volume (Bloemers et al., 2010). Such tools are particularly useful to assess phenomena that may only occur over longer periods of time and/or directly in people's natural environments (Gunthert \& Wenze, 2012). Participants may also feel more at ease in their natural environment compared to laboratory settings, which may in turn allow the expression of sexual behaviors and response that more closely approaches their usual patterns. For instance, Bloemers and colleagues (2010) found that, in healthy women, genital sexual arousal was significantly increased when measured at home compared to laboratory settings.

The downside of these natural environment studies, however, is that they depend on participants closely following instructions (e.g., properly complete the tasks or questionnaires; Gunthert \& Wenze, 2012), and they make it difficult for researchers to control environmental conditions that may influence the behaviors or responses of research participants (Lehmiller, 2017). And unless researchers have ambulatory set-ups, as in Bloemers and colleagues (2010), these studies also make it difficult to bring the laboratory equipment into people's natural environments and/or teach them how to use them properly, as this process may be overly expensive, time consuming, and augment the risk of damaging equipment.

Consequently, to get a more accurate and comprehensive picture of human eroticism, sex researchers must triangulate the results obtained from the various methods described above. Then, after years of accumulated data, this triangulation process may lead to more conclusive findings about human intimacy, sexuality, and their related phenomena. Yet, this process not only takes a tremendous amount of time, financial, and human resources, but the methods previously described also present several limitations. For one, self-report measures often used in sex research may be constrained by participant's memory, the quality of their self-assessment, and social-desirability bias (Lehmiller, 2017). Prospective questions about participants' likely sexual or intimate behaviors in future or hypothetical scenarios may also not reveal people's true tendencies in real-life situations (Skakoon-Sparling et al., 2016). Lastly, the methods described above may not adequately capture real-world sex or intimate relationships, while also preventing the exploration of risky phenomena (Lehmiller, 2017). To 
bridge these gaps, sex researchers must develop safe, ethical, and controllable research tools that more closely approach real-world intimacy and sexuality.

\section{EROBOTICS: A POTENTIAL SOLUTION TO THE ETHICAL \& METHODOLOGICAL CHALLENGES OF SEXOLOGY}

As a transdisciplinary field of research, erobotics aims to develop theoretical, clinical, and experimental research methods to explore the wide range of phenomena pertaining to our sexual and intimate relationships with artificial agents (Dubé \& Anctil, 2020). In relation to the development of experimental methods, it has been proposed that the various types of erobots could be employed as standardized research tools in and outside of laboratory settings (Dubé \& Anctil, 2020).

The term erobots refers to: "all artificial erotic agents, as well as their enabling technologies, and interconnected, multilayered, and multi-agent systems" (Dubé \& Anctil, 2021, p. 1). Erobots are specialized (multi-)agent systems, as they can display capabilities, behaviors, and/or persona that are perceived as erotic (e.g., sexual or romantic; Dubé \& Anctil, 2020). Their agency - or their capability to act in/on the world to achieve goals on their own (Schlosser, 2015) - may vary greatly as a function of the technologies that sustain them, which is likely to become evermore powerful, sophisticated, and combined in the coming years (Dubé \& Anctil, 2020). Such technologies include but are not limited to: artificial intelligence (AI), robotics, cloud-computing, natural language processing, emotional recognition, haptic equipment, the Internet of Things/Senses (IoT/S), as well as virtual, augmented, and mixed realities (VR, AR, MR; Dubé \& Anctil, 2020).

Erobots can be embodied, like in the case of the sex or love robots produced by companies such as Realbotix (2020) and DSDolls (n.d.). They can also be virtual, as in artificial companions like Replika ((n.d.)) and Xiaoice (Liao, 2020). And finally, they can be augmented, in the sense that they may result from the use of augmentative technologies, such as products like Hybri (2020) or Artificial Intelligent MatchMaker (AIMM, 2020; Dubé \& Anctil, 2021). Noteworthy, erobots can be simultaneously embodied, virtual, or augmented, since their systems, memory, and AI can be cloud-based or connected through the IoT/S (Dubé \& Anctil, 2020). Yet, what distinguishes the different taxon is how they are interactively perceived by humans, or in this case, whether we perceive these agents as acting in/on virtual environments, our non-virtual world, or both (Dubé \& Anctil, 2020).

\subsection{The main advantages of erobots for sexology}

Erobots present several advantages for sex research. For one, equipped with the right sensors and actuators, erobots could act as both the stimuli and a recording apparatus (Dubé \& Anctil, 2020; González-González, Gil-Iranzo, \& Paderewski-Rodríguez, 2021; Zhou, Zhao, \& Liang, 2020). As such, they can be on the giving and receiving end of the sexual and intimate interactions (Samani, Cheok, \& Fernando, 2011). These systems can also facilitate the access to data that may otherwise be difficult to examine, such as reciprocal touch and coordinated (micro-)movements, in laboratory settings or from the comfort of people's natural environments (Cheok, Levy, \& Karunanayaka, 2016). In addition, the numbers, forms, and behaviors of erobots can be pre-programmed and/or manipulated to deliver specific stimuli and isolate the effects of different variables on human sociosexual behaviors and responses regardless of people's gender/sex, orientation/preferences, identities, lifestyles, etc. (MacDorman \& Ishiguro, 2006; van Anders, 2015). Equipped with cloud-based, hivemind-type 
of cognition or intelligence (Kim \& Lim, 2019), these machines can also learn from multiple users simultaneously and manipulate their parameters on a large scale to rapidly test the influence of different variables on human intimacy and sexuality (Zhou et al., 2020).

Erobots also eliminate the need for multiple participants to partake in experiments that may require human interactions or study confederates (Dubé \& Anctil, 2020). Compared to humans (e.g., experimenters, study confederates, or other research participants), erobots also have the potential to deliver the same controlled erotic stimulation to all participants systematically and repeatedly. And by being fully under human control, they reduce the risks related to interhuman intimacy and sexuality (Dubé $\&$ Anctil, 2020). For example, erobots can be easily cleaned to ensure sanitary standards. Experimenters and participants can also terminate the experiment immediately on command if they ever felt uncomfortable in intimate or sexual situations with a machine. And since erobots cannot be hurt, participants could explore aspects of their eroticism that may not be able to act on or feel comfortable sharing with other humans.

Granted that, the immediacy of the sociosexual interactions that people may have with erobots could also allow participants to answer questions about their experience during, or at the very least, immediately after an erotic experience, rather than rely on their (long-term) memory. In addition, the potential capability of erobots to emulate the human erotic behaviors and responses could allow researchers to approach the type of sexual experiences that people have in real-world settings. Together, this may improve the ecological validity of experimental paradigms in sexology, along with the generalizability of their findings (Dubé \& Anctil, 2020).

Notably, these methodological principles are already being applied in research on human-machine interactions, cognitive sciences, as well as psychology and sexology. For instance, studies in Android Science suggest that increasingly humanlike robots offer new experimental apparatus, since machines that progressively emulate human appearance and behaviors seem to elicit responses that more closely approach real-world, interhuman interactions (MacDorman \& Ishiguro, 2006; Ishiguro, 2007; Urgen et al., 2013). MacDorman and Ishiguro (2006) argued that an android - or "an artificial system designed with the ultimate goal of being indistinguishable from humans in its external appearance and behavior" - would hold the potential to elicit the cognitive models and psychophysiological responses that a person would normally have with another human, especially if they did not know the nature of the agent (i.e., artificial). This seems supported by neurorobotics studies such as Urgen and colleagues (2013), who found that androids elicited the same brain responses as humans, but not robots that exhibited machine-like cues.

With regard to human sexuality, more specifically, some laboratories currently employ VR in combination with other measures to deliver more realistic and adapted erotic stimuli, which researchers can manipulate to assess their effects on humans sexual behaviors and responses (Dekker et al., 2020; Elsey et al., 2019; Fromberger et al., 2015; Renaud et al., 2002). It has also been argued that these same technologies may be applied to sex therapy in order to assist with the assessment and development of treatments or interventions for sexual dysfunctions, phobias, and problematic behaviors (Lafortune, Dion, \& Renaud, 2019).

For instance, Renaud and colleagues (2013) showed that VR-based agent could be used to distinguish between the sexual arousal response and gaze behavior of minor-attracted individuals and people attracted to adults. Loranger and Bouchard (2017) further showed that VR could be employed to assess and potentially help treat victims of sexual assault by exposing them to a safe and controlled virtual encounter with an aggressor. More recently, Milani and colleagues (2021) demonstrated that, compared to two-dimensional sexually explicit video, VR three-dimensional women-centered erotica elicited greater general presence (i.e., being there), sexual presence, and sexual arousal, with the 
experience of sexual presence being higher when the stimuli were presented from a first-person point of view, compared to a third-person point of view. Lastly, Lafortune et al. (In press) showed that VR could efficiently elicit aversive reactions typical to sexual aversion (SA), such as anxiety and disgust, in high-SA individuals, suggesting that VR could be used to assess SA and possibly be employed to deliver exposure-based treatments.

These same principles could be applied, in the future, to embodied and augmented artificial agents, which could also be used to deliver safe, controlled, and ever-more realistic erotic stimuli. Still, the full potential of erobotic technologies has yet to be leveraged. This is likely in part due to the current relative novelty, high cost, and unsophistication of some of these technologies (e.g., sex robots; Döring, Mohseni, Walter, 2020). It may also be due to sexual taboos and the conservative sexual views of some research ethics boards regarding sexological science, which is often disguised under a "precautionary principle argument."

Yet, in line with the proposition made by Shaughnessy \& Braham (2021) regarding the use of online technologies, we argue that erobotic technologies could play a greater role in sexuality studies. We also argue that, by reducing risks, erobotic technologies could help overcome the ideological resistance that some research ethics boards have, and in turn help sexological science move forward by demonstrating that it is possible to conduct more interactive sex studies safely and ethically both in and outside laboratory settings. Moreover, we propose that while erobots that are indistinguishable from human could potentially provide an ideal experimental apparatus to investigate interhuman relationships, sexual responses elicited by other humans, or human interactions with hyper-realistic humanlike erobots, erotic machines and systems that do not reach this level of sophistication or differ from human forms and behaviors would still be useful to sexology, as shown by the results already obtained with VR. Specifically, these technologies allow us to gather data more ethically and safely, while progressively approaching more ecologically valid erotic stimuli. More to the point, they can also serve to investigate erotic phenomena related to solitary or partnered sexuality, as well as eroticism that pertain to human interactions with entities that markedly differ from human forms and behaviors.

Importantly, given the current pace of technological development, it can be reasonably anticipated that more advanced erotbotic technologies may soon become accessible to sex researchers (Dubé \& Anctil, 2020). Thus, sex researchers may want to take advantage of this opportunity and plan for the development of erobots as research tools, along with their integration into sexology. As such, the present paper reviews some of the strengths and weaknesses of erobots in order to help sex scientists make educated, resource-efficient decisions about what technology they may use in their sexological research projects.

\section{STRENGTHS \& WEAKNESSES OF EROBOTS}

As research tools, each taxon of erobots presents a set of relative strengths and weaknesses (for a summary, see Table 1). Embodied erobots, for instance, can advantageously interact with our nonvirtual world. The corporeality of machines like sex or love robots allows them to touch and be touched directly by users without having to rely on other equipment. This may help ensure the realism of the erotic experiences - e.g., their sensations and perceptions, as well as the feeling of social and sexual presence. Equipped with the right sensors - visual, tactile, audio, heat, or otherwise embodied erobots could also capture aspects of partnered intimate and sexual interactions, which are currently difficult or impossible to examine in experimental settings and paradigms involving human 
Table 1

Summary of the current relative strengths and weaknesses of erobots

\begin{tabular}{|c|c|c|c|c|c|c|}
\hline \multirow[t]{2}{*}{ Characteristics } & \multicolumn{2}{|l|}{ Embodied } & \multicolumn{2}{|l|}{ Virtual } & \multicolumn{2}{|c|}{ Augmented } \\
\hline & Strengths & Weaknesses & Strengths & Weaknesses & Strengths & Weaknesses \\
\hline Cost & - & High & Low & - & - & High \\
\hline $\begin{array}{l}\text { Level of } \\
\text { sophistication }\end{array}$ & - & Low & Moderate & - & - & Low \\
\hline $\begin{array}{l}\text { Versatility/customiz- } \\
\text { ability }\end{array}$ & - & Low & High & - & High & - \\
\hline $\begin{array}{l}\text { Interaction with } \\
\text { non-virtual world }\end{array}$ & Yes & - & - & No & - & No \\
\hline $\begin{array}{l}\text { Interaction with } \\
\text { virtual world }\end{array}$ & - & No & Yes & - & Yes & - \\
\hline $\begin{array}{l}\text { Manipulation of the } \\
\text { environment }\end{array}$ & - & No & Yes & - & Yes & - \\
\hline Access to data & \multicolumn{2}{|c|}{$\begin{array}{l}\text { Bodily sensors and non-VR } \\
\text { world }\end{array}$} & \multicolumn{2}{|c|}{$\begin{array}{l}\text { VR equipment and VR } \\
\text { world }\end{array}$} & \multicolumn{2}{|c|}{$\begin{array}{l}\text { AR-equipment and VR \& } \\
\text { non-VR worlds }\end{array}$} \\
\hline
\end{tabular}

partners. The potential modularity of embodied machines could also make them relatively versatile and allow designers and scientists to tailor their forms and/or behaviors to the needs of different research projects.

At the moment, however, the technology that may eventually sustain convincing sociosexual robotics or generate compelling interactions that approach real-world eroticism, remains relatively unsophisticated and expensive (e.g., the current price of robotic-headed dolls is \$6000-15000 USD; Döring, 2021; RealdollX, 2021). Compared to other types of erobots, embodied erobots may also: take more space and material; be constrained by the laws of physics governing our non-virtual world (e.g., not be able to fly or perform impossible behaviors like virtual characters could); and not be as versatile in terms of their features (e.g., bodily characteristics). Additionally, compared to other erobots, embodied machines do not allow research to manipulate the environments in which they appear or the features of the participants/users themselves (e.g., appearance; Veenhof, 2020); the data gathered through them directly is also limited to the sensors that are nested in the machines' body; and they may not be as easily duplicated. So unless a researcher has multiple machines, it may be more difficult to explore phenomena that require interacting with more than one partner.

Comparatively, virtual erobots are highly versatile in terms of their form, behaviors, as well as the researcher's ability to adjust their related virtual environments (Lafortune et al., 2019). The incorporeality of virtual erobots also allows them to be infinitely duplicated and enables users to interact with them at a distance. Furthermore, in recent years, the technology and equipment that sustain VR experiences has not only drastically improved in terms of quality, power, and realisms, but has also become much more financially accessible and easily distributed via online platforms. For example, the price of the Oculus Quest 2 VR headset ranges from $\$ 459$ to $\$ 628$ CAD; Facebook Technologies, LLC, (n.d.)), and virtual companions, like Replika, are also downloadable on iOS and Android devices for free or for $\$ 7.99$ per month for more advanced versions (Replika, (n.d.)). This allows VR technology and virtual erobots to be deployed on a larger scale and be used relatively easily in both laboratory settings and from the comfort of one's natural environments.

Combined with upcoming full-bodied haptic equipment (e.g., Teslasuit; VR Electronics Ltd., 2021), the data being gathered about users' responses and behaviors could potentially encapsulate everything that people do as they interact with the virtual partners and environments - ranging from what they see or touch, to their psychophysiological reactions to those experiences. In VR, participants may also 
change their features or that of their avatars to partly experience what it would be like to be something or someone else during erotic interactions (Veenhof, 2020). And the same goes for the other people with whom a participant may sociosexually interact with in a virtual environment. Conjoined with its versatility, this may explain why VR is increasingly used in experimental settings - including in sexology (Lafortune et al., 2019) - and why it may continue to dominate the research and clinical markets in the coming years.

Still, like other erobotic technologies, virtual erobots remain constrained by the quality and accessibility of their underlying equipment and systems (e.g., goggles and computers), along with their capability to generate feelings of social and sexual presence (Fontanesi \& Renaud, 2014). Moreover, they limit the erotic experiences to what is happening in the virtual world. Although this allows researchers to control environmental factors or possibly explore the impact of different scenarios on human eroticism, the intimacy and sexuality of most people takes place, for the greater part, in nonvirtual environments. As such, while it may be informative to use VR, it may still be more useful to employ embodied or augmented erobots to answer some research questions.

Finally, the main advantage of augmented erobots over other artificial erotic agents is their ability to blend with and/or be projected onto a non-virtual world (Dubé \& Anctil, 2020; Grzegorczyk, Slimwinski, \& Kaczmarek, 2019; Rubin, 2018). As such, augmented erobots combine several important strengths of embodied and virtual erobots. They are versatile, easily duplicated, and can potentially be used in both laboratory settings and natural environments. They can also be used at a distance by multiple individuals simultaneously and allow users to modify themselves, their partners, or their environment during erotic experiences. What's more, they can record everything that VR systems can, in addition to what is happening in the non-virtual environments where users are situated.

That said, like embodied erobots, the technology underlying augmented erobots is still in its infancy and remains mostly inaccessible or expensive (e.g., Microsoft's HoloLens 2 is \$3500-5199 USD; Microsoft, 2021). Augmented erobots may also not be able to directly interact with people's non-virtual environment beyond what their connected equipment allows - e.g., glasses or haptic suits. Thus, augmented erobots may eventually become important research tools for sexologists, direct engagement with our non-virtual world may remain the main selling point for embodied machines.

Again, it is important to note that the different types of erobots can be connected and share data with one another (Dubé \& Anctil, 2020). This means that machines and researchers may eventually be able to triangulate their results and tailor erobots' responses to simultaneously investigate various aspects of human eroticism on a large scale. Ultimately, whether this becomes possible or not in the future, the choice of using a type of erobot over another will likely remain heavily dependent on the research questions being asked and the objectives of the study.

\section{CONCLUSION}

The days of Masters and Johnson are gone, but their objective of understanding human sexuality remains. Emerging erobotics technologies offer new tools for contemporary sex researchers to conduct ethical studies that also improve the validity of experimental paradigms in sexology. To argue this point, this paper highlighted the ethical and methodological challenges of modern sexological research; reviewed the main advantages of erobots as research tools in and outside laboratories; and discussed their relative strength and weaknesses of embodied, virtual, and augmented artificial erotic agents. 
Yet, to enable the benefits of erobotic technologies for sexology, we propose that further partnerships between academia and the private sector will need to be developed. These mutually beneficial partnerships may allow scientists to inform the design and development of adapted research tools, while also allowing businesses and entrepreneurs to test their products, develop new clientele and markets (i.e., researchers and science), as well as ensure that their creations contribute to the improvement of human health and well-being.

As a concluding remark, we propose that technology - such as erobots and their systems - may allow scientists to decipher patterns in human intimacy and sexuality unseen before - especially if they are deployed on a sufficiently large scale. In time, the cumulative data and knowledge gathered through erobotic technologies may allow us to gain a holistic picture of human eroticism, and in turn, provide a deeper understanding of our intimate and sexual selves.

\section{ACKNOWLEDGEMENTS}

The authors would also like to thank the Fonds de Recherche du Québec-Santé (FRQS) and Société et culture (FRQSC) for financially supporting the doctoral training of Simon Dubé and Maria Santaguida.

\section{REFERENCES}

AIMM (2020). The Talking Artificial Intelligent Matchmaker. AIMM. https://aimm.online.

Andrade, C. (2018). Internal, external, and ecological validity in research design, conduct, and evaluation. Indian Journal of Psychological Medicine, 40(5), 498-499. doi:10.4103/IJPSYM.IJPSYM_ 334_18.

Basson, R. (2000). The female sexual response: A different model. Journal of Sex \& Marital Therapy, 26(1), 51-65. doi:10.1080/009262300278641.

Binik, Y.M., Mah, K. \& Kiesler, S. (1999). Ethical issues in conducting sex research on the Internet. The Journal of Sex Research, 36(1), 82-90. doi:10.1080/00224499909551971.

Bloemers, J., Gerritsen, J., Bults, R., Koppeschaar, H., Everaerd, W., Olivier, B. \& Tuiten, A. (2010). Induction of sexual arousal in women under conditions of institutional and ambulatory laboratory circumstances: A comparative study. The Journal of Sexual Medicine, 7(3), 1160-1176. doi:10.1111/ j.1743-6109.2009.01660.x.

Both, S., Brauer, M. \& Laan, E. (2011). Classical conditioning of sexual response in women: A replication study. The Journal of Sexual Medicine, 8(11), 3116-3131. doi:10.1111/j.1743-6109.2011. 02453.x.

Brody, S. \& Krüger, T.H.C. (2006). The post-orgasmic prolactin increase following intercourse is greater than following masturbation and suggests greater satiety. Biological Psychology, 71(3), 312-315. doi:10.1016/j.biopsycho.2005.06.008.

Cheok, A.D., Levy, D. \& Karunanayaka, K. (2016). Lovotics: Love and sex with robots. In K. Karpouzis and G. Yannakakis (Eds.), Emotion in Games (pp. 303-328). Springer. doi:10.1007/978-3319-41316-7_18. 
Chivers, M.L., Seto, M.C., Lalumière, M.L., Laan, E. \& Grimbos, T. (2010). Agreement of selfreported and genital measures of sexual arousal in men and women: A meta-analysis. Archives of Sexual Behavior, 39, 5-56. doi:10.1007/s10508-009-9556-9.

Davis, K.C., Parrott, D.J., George, W.H., Tharp, A.T., Hall, G.C.N. \& Stappenbeck, C.A. (2014). Studying sexual aggression: A review of the evolution and validity of laboratory paradigms. Psychology of Violence, 4(4), 462-476. doi:10.1037/a0037662.

Dekker, A., Wenzlaff, F., Biedermann, S.V., Briken, P. \& Fuss, J. (2020). VR porn as "empathy machine"? Perception of self and others in virtual reality pornography. The Journal of Sex Research, 58(3), 273-278. doi:10.1080/00224499.2020.1856316.

Dir, A.L., Coskunpinar, A. \& Cyders, M.A. (2014). A meta-analytic review of the relationship between adolescent risky sexual behavior and impulsivity across gender, age, and race. Clinical Psychology Review, 34(7), 551-562. doi:10.1016/j.cpr.2014.08.004.

Döring, N. (2021). Sex dolls and sex robots. In A.D. Lykins (Ed.), Encyclopedia of Sexuality and Gender. Springer. doi:10.1007/978-3-319-59531-3_63-2.

Döring, N., Mohseni, M.R. \& Walter, R. (2020). Design, use and effects of sex dolls and sex robots: Scoping review. Journal of Medical Internet Research, 22(7), e18551. doi:10.2196/18551.

DS doll. (n.d.). Ex doll. Real doll collection. http://www.realdollcollection.com/exdoll.

Dubé, S. \& Anctil, D. (2020). Foundations of erobotics. International Journal of Social Robotics, 13(5), 1205-1233. doi:10.1007/s12369-020-00706-0.

Dubé, S. \& Anctil, D. (2021). Erobots and erobotics. In A.D. Lykins (Ed.), Encyclopedia of Sexuality and Gender. Springer. doi:10.1007/978-3-319-59531-3_100-1.

Elsey, J.W.B., van Andel, K., Kater, R.B., Reints, I.M. \& Spiering, M. (2019). The impact of virtual reality versus 2D pornography on sexual arousal and presence. Computers in Human Behavior, 97, 35-43. doi:10.1016/j.chb.2019.02.031.

Exton, M.S., Krüger, T.H.C., Koch, M., Paulson, E., Knapp, W., Hartmann, U. \& Schedlowski, M. (2001). Coitus-induced orgasm stimulates prolactin secretion in healthy subjects. Psychoneuroendocrinology, 26(3), 287-294. doi:10.1016/S0306-4530(00)00053-6.

Facebook Technologies, LLC. (n.d.). Oculus Quest 2. Facebook. https://www.oculus.com/quest-2/.

Fontanesi, L. \& Renaud, P. (2014). Sexual presence: Toward a model inspired by evolutionary psychology. New Ideas in Psychology, 33, 1-7. doi:10.1016/j.newideapsych.2013.10.001.

Fromberger, P., Meyer, S., Kempf, C., Jordan, K. \& Müller, J.L. (2015). Virtual viewing time: The relationship between presence and sexual interest in androphilic and gynephilic men. PLOS ONE, 10(5), e0127156. doi:10.1371/journal.pone.0127156.

González-González, C.S., Gil-Iranzo, R.M. \& Paderewski-Rodríguez, P. (2021). Human-robot interaction and sexbots: A systematic literature review. Sensors, 21(1), 1-18. doi:10.1109/JSEN.2020. 3039123.

Government of Canada (2019). Tri-Council policy statement: Ethical conduct for research involving humans - TCPS2 2018. https://ethics.gc.ca/eng/documents/tcps2-2018-en-interactive-final.pdf.

Grzegorczyk, T., Slimwinski, R. \& Kaczmarek, J. (2019). Attractiveness of augmented reality to consumers. Technology Analysis \& Strategic Management, 31(11), 1257-1269. doi:10.1080/09537325. 2019.1603368 . 
Gueguen, N. (2009). The receptivity of women to courtship solicitation across the menstrual cycle: A field experiment. Biological Psychology, 80(3), 321-324. doi:10.1016/j.biopsycho.2008.11.004.

Gunthert, K.C. \& Wenze, S.J. (2012). Daily diary methods. In M.R. Mehl and T.S. Conner (Eds.), Handbook of Research Methods for Studying Daily Life (pp. 144-159). The Guilford Press.

Huberman, J.S. \& Chivers, M.L. (2015). Examining gender specificity of sexual response with concurrent thermography and plethysmography. Psychophysiology, 52(10), 1382-1395. doi:10.1111/psyp. 12466.

Hybri (2020). Mixed reality: The digital human AI partner. Hybri. https://whatisthehybri.com/.

Ishiguro, H. (2007). Android science: Toward a new cross-interdisciplinary framework. In S. Thrun, R. Brooks and H. Durrant-Whyte (Eds.), Robotics Research. Springer. doi:10.1007/978-3-540-481133_11.

Kim, T.Y. \& Lim, J.B. (2019). An edge cloud-based body data sensing architecture for artificial intelligence computation. International Journal of Distributed Sensor Networks, 15(4), 1-12. doi:10. $1177 / 1550147719839014$.

Kite, M.E. \& Whitley, B.E. (2018). Principles of Research in Behavioral Science (4 ${ }^{\text {th }}$ ed.). Routledge. doi:10.4324/9781315450087.

Lafortune, D., Dion, L. \& Renaud, P. (2019). Virtual reality and sex therapy: Future directions for clinical research. Journal of Sex \& Marital Therapy, 46(1), 1-17. doi:10.1080/0092623X.2019.1623357.

Lafortune, D., Lapointe, V., Canivet, C., Godbout, N. \& Boislard-Pépin, M.-A. (In press). Validation of a virtual environment for sexual aversion. Journal of Behavioral and Cognitive Therapy.

Lehmiller, J.J. (2017). The Psychology of Human Sexuality. Wiley-Blackwell.

Liao, R. (2020). Microsoft spins out 5-year-old Chinese chatbot Xiaoice. https://techcrunch.com/ 2020/07/12/microsoft-spins-out-5-year-old-chinese-chatbot-xiaoice/.

Loranger, C. \& Bouchard, S. (2017). Validating a virtual environment for sexual assault victims. Journal of Traumatic Stress, 30(2), 157-165. doi:10.1002/jts.22170.

MacDorman, K.F. \& Ishiguro, H. (2006). The uncanny advantage of using androids in cognitive and social science research. Interaction Studies, 7(3), 297-337. doi:10.1075/is.7.3.03mac.

Masters, W.H. \& Johnson, V.E. (1966). Human Sexual Response. Bantam Books.

Masters, W.H. \& Johnson, V.E. (1970). Human Sexual Inadequacy. Bantam Book.

Masters, W.H., Johnson, V.E. \& Kolodny, R.C. (1977). Ethical Issues in Sex Therapy and Research (Vol. 1). Boston: Little, Brown, and Company.

Masters, W.H., Johnson, V.E. \& Kolodny, R.C. (1988). Masters and Johnson on Sex and Human Loving. Little, Brown and Company.

Masters, W.H., Johnson, V.E. \& Kolodny, R.C. (1994). Heterosexuality. HarperCollins.

Masters, W.H., Johnson, V.E., Kolodny, R.C. \& Weems, S.M. (1980). Ethical Issues in Sex Therapy and Research (Vol. 2). Little, Brown, and Company.

Metcalfe, A., Talavlikar, R., du Prey, B. \& Tough, S.C. (2016). Exploring the relationship between socioeconomic factors, method of contraception and unintended pregnancy. Reproductive Health, 13(28), 1-8. doi:10.1186/s12978-016-0151-y.

Microsoft (2021). HoloLens 2. Microsoft. https://www.microsoft.com/en-us/hololens/buy. 
Milani, S., Jabs, F., Brown, N., Zdaniuk, B., Kindstone, A. \& Brotto, L. (2021). Virtual reality erotica: Exploring general presence, sexual presence, sexual arousal, and sexual desire in women. Archives of Sexual Behavior, 1-12. doi:10.1007/s10508-021-02111-8.

Milhausen, R.R., Sakaluk, J.K., Fisher, T.D., Davis, C.M. \& Yarber, W.L. (2020). Handbook of Sexuality-Related Measures (4 ${ }^{\text {th }}$ ed.). Routledge.

Mitchell, K.R., Mercer, C.H., Ploubidis, G.B., Jones, K.G., Datta, J., Field, N., Copas, A.J., Wellings, K., et al. (2013). Sexual function in Britain: Findings from the third national survey of sexual attitudes and lifestyles (Natsal-3). The Lancet, 382(9907), 1817-1829. doi:10.1016/S0140-6736(13)62366-1.

Munck, E. (1999). Ethics of sexuality - ethics of sexology. Scandinavian Journal of Sexology, 2(4), 195-201.

Ortigue, S., Patel, N. \& Bianchi-Demicheli, F. (2009). New electroencephalogram (EEG) neuroimaging methods of analyzing brain activity applicable to the study of human sexual response. The Journal of Sexual Medicine, 6(7), 1830-1845. doi:10.1111/j.1743-6109.2009.01271.x.

Parada, M., Gérard, M., Larcher, K., Dagher, A. \& Binik, Y.M. (2018). How hot are they? Neural correlates of genital arousal: An infrared thermographic and functional magnetic resonance imaging study of sexual arousal in men and women. The Journal of Sexual Medicine, 15(2), 217-229. doi:10. 1016/j.jsxm.2017.12.006.

Pascual-Leone, A., Singh, T. \& Scoboria, A. (2010). Using deception ethically: Practical research guidelines for researchers and reviewers. Canadian Psychology/Psychologie canadienne, 51(4), 241-248. doi:10.1037/a0021119.

Prause, N., Kuang, L., Lee, P. \& Miller, G. (2016). Clitorally stimulated orgasms are associated with better control of sexual desire, and not associated with depression or anxiety, compared with vaginally stimulated orgasms. The Journal of Sexual Medicine, 13(11), 1676-1685. doi:10.1016/j.jsxm.2016. 08.014 .

Price, G.C., Jansen, K.L. \& Weick, M.R. (2020). Let's talk about sex: Ethical considerations in survey research with minority populations. Translational Issues in Psychological Science, 6(3), 214-222. doi:10.1037/tps0000270.

Råheim, M., Magnussen, L.H., Sekse, R.J.T., Lunde, Å., Jacobsen, T. \& Blystad, A. (2016). Researcher-researched relationship in qualitative research: Shifts in positions and researcher vulnerability. International Journal of Qualitative Studies on Health and Well-being, 11, 1-12. doi:10.3402/ qhw.v11.30996.

Realbotix (2020). We specialize in. Realbotix. https://realbotix.com/.

RealDollX (2021). What is RealdollX?. Realdoll. https://www.realdoll.com/realdoll-x/.

Renaud, P., Chartier, S., Rouleau, J.L., Proulx, J., Goyette, M., Trottier, D., Bouchard, S., et al. (2013). Using immersive virtual reality and ecological psychology to probe into child molesters' phenomenology. Journal of Sexual Aggression, 19(1), 102-120. doi:10.1080/13552600.2011.617014.

Renaud, P., Rouleau, J.L., Granger, L., Barsetti, I. \& Bouchard, S. (2002). Measuring sexual preferences in virtual reality: A pilot study. CyberPsychology \& Behavior, 5(1), 1-9. doi:10.1089/ 109493102753685836.

Replika (n.d.). The AI companion who cares. Replika. https://replika.ai/.

Riley, A. \& Scott, E. (1999). Ethics in research into human sexuality and into sexual and relationship therapy. Sexual and Marital Therapy, 4(3). doi:10.1080/02674659908405413. 
Rosewarne, L. (2017). The Internet and research methods in the study of sex research: Investigating the good, the bad, and the (un)ethical. In P. Liamputtong (Ed.), Handbook of Research Methods in Health Social Sciences. Springer. doi:10.1007/978-981-10-2779-6_140-1.

Rosoff, C.B. (2018). Ethics in college sexual assault research. Ethics \& Behavior, 28(2), 91-103. doi:10.1080/10508422.2017.1333001.

Rowland, D.L. (1999). Issues in the laboratory study of human sexual response: A synthesis for the nontechnical sexologist. The Journal of Sex Research, 36(1), 3-15. https://www.jstor.org/stable/ 3813626. doi:10.1080/00224499909551962.

Rubin, P. (2018). Future presence: How virtual reality is changing human connection, intimacy, and the limits of ordinary life. HarperOne.

Samani, H.A., Cheok, A.D. \& Fernando, O.N.N. (2011). An affective interactive audio interface for Lovotics. Computers in Entertainment, 9(2), 1-14. doi:10.1145/1998376.1998377.

Schlosser, M. (2015). Agency. In E.N. Zalta (Ed.), The Stanford Encyclopedia of Philosophy. https:// plato.stanford.edu/archives/fall2015/entries/agency/.

Scott-Sheldon, L.A.J., Walstrom, P., Carey, K.B., Johnson, B.T. \& Carey, M.P. (2013). Alcohol use and sexual risk behaviors among individuals infected with HIV: A systematic review and metaanalysis 2012 to early 2013. Current HIV/AIDS Reports, 10, 314-323. doi:10.1007/s11904-0130177-5.

Shaughnessy, K. \& Braham, J. (2021). Where's the tech in sex research? A brief critique and call for research. The Canadian Journal of Human Sexuality. doi:10.3138/cjhs.2021-0026.

Shirmohammadi, M., Kohan, S., Shamsi-Gooshki, E. \& Shahriari, M. (2018). Ethical considerations in sexual health research: A narrative review. Iranian Journal of Nursing and Midwifery Research, 23, 157-166. doi:10.4103/ijnmr.IJNMR_60_17.

Sidorkewicz, N. \& McGill, S.M. (2014). Male spine motion during coitus. Spine, 39(20), 1633-1639. doi:10.1097/BRS.0000000000000518.

Skakoon-Sparling, S., Cramer, K.M. \& Shuper, P.A. (2016). The impact of sexual arousal on sexual risk-taking and decision-making in men and women. Archives of Sexual Behavior, 45, 33-42. doi:10. 1007/s10508-015-0589-y.

Smith, P. \& Waterman, M. (2005). Sex differences in processing aggression words using the emotional Stroop task. Aggressive Behavior, 31(3), 271-282. doi:10.1002/ab.20071.

Sriram, N. \& Greenwald, A.G. (2009). The brief implicit association test. Experimental Psychology, 56(4), 283-294. doi:10.1027/1618-3169.56.4.283.

Suschinsky, K.D. \& Lalumière, M.L. (2012). Is sexual concordance related to awareness of physiological states? Archives of Sexual Behavior, 41(1), 199-208. doi:10.1007/s10508-012-9931-9.

Urgen, B.A., Plank, M., Ishiguro, H., Poizner, H. \& Saygin, A.P. (2013). EEG Theta and Mu oscillations during perception of human and robot actions. Frontiers in Neurorobotics, 7(19), 1-13. doi:10. 3389/fnbot.2013.00019.

Vaillancourt-Morel, M.-P., Rosen, N.O., Willoughby, B.J., Leonhardt, N.D. \& Bergeron, S. (2020). Pornography use and romantic relationships: A dyadic daily diary study. Journal of Social and Personal Relationships, 37(10-11), 2802-2821. doi:10.1177/0265407520940048. 
van Anders, S.M. (2015). Beyond sexual orientation: Integrating gender/sex and diverse sexualities via sexual configurations theory. Archives of Sexual Behavior, 44(5), 1177-1213. doi:10.1007/ s10508-015-0490-8.

van Lankveld, J., Hubben, D., Dewitte, M., Dingemans, M.E., den Butter, C. \& Grauvogl, A. (2014). The partner's presence in the sex research lab differentially affects sexual arousal in women and men. The Journal of Sexual Medicine, 11(3), 697-708. doi:10.1111/jsm.12406.

Veenhof, S. (2020). How to be your own robot when wearing augmented reality glasses. Journal of Future Robot Life, 1(1), 17-22. doi:10.3233/FRL-200005.

VR Electronics Ltd. (2021). Teslasuit. VR Electronics Ltd. https://teslasuit.io/.

Watter, D.N. (2020). Ethical issues in clinical sexology. In M. Lew-Starowicz, A. Giraldi and T. Krüger (Eds.), Psychiatry and Sexual Medicine (pp. 33-45). Springer. doi:10.1007/978-3-03052298-8_4.

Wenzlaff, F., Peer Briken, P. \& Dekker, A. (2016). Video-based eye tracking in sex research: A systematic literature review. The Journal of Sex Research, 53(8), 1008-1019. doi:10.1080/00224499. 2015.1107524.

Wise, N.J., Frangos, E. \& Komisaruk, B.R. (2017). Brain activity unique to orgasm in women: An fMRI analysis. The Journal of Sexual Medicine, 14(11), 1380-1391. doi:10.1016/j.jsxm.2017.08.014.

Zapien, N. (2017). Participation bias and social desirability effects in research on extramarital affairs: Considerations of meaning and implications for sexual behavior research. Archives of Sexual Behavior, 46, 1565-1571. doi:10.1007/s10508-017-1020-7.

Zhang, X.-D., Luk, S.C.Y., Han, Y.-H., Chen, G.-R., Zhang, G.-L., Zhu, B.-S. \& Luchters, S. (2019). Ethical considerations for conducting sexual and reproductive health research with female adolescents engaged in high-risk behaviours in China. Sexual \& Reproductive Healthcare, 20, 46-53. doi:10.1016/ j.srhc.2019.02.005.

Zhou, Z., Zhao, J. \& Liang, X. (2020). Cyberphysical human sexual behaviour acquisition system (SeBA): Development and implementation study in China. JMIR mHealth uHealth, 8(4), 1-10. doi:10. 2196/12677. 